\title{
AMENDMENTS
}

\section{Author Correction: Potential impacts and challenges of border carbon adjustments}

Christoph Böhringer (D), Carolyn Fischer (1D), Knut Einar Rosendahl(D) and Thomas Fox Rutherford

Correction to: Nature Climate Change https://doi.org/10.1038/s41558-021-01250-z, published online 3 January 2022.

In the version of this article initially published, the third affiliation for Carolyn Fischer (Development Research Group, World Bank, Washington, DC, USA) was not included. The affiliation has been added to the HTML and PDF versions of the article.

Published online: 31 January 2022

https://doi.org/10.1038/s41558-022-01300-0

๑) Springer Nature Limited 2022

\section{Author Correction: Enhanced risk of concurrent regional droughts with increased ENSO variability and warming \\ Jitendra Singh (1), Moetasim Ashfaq (D), Christopher B. Skinner, Weston B. Anderson (1), Vimal Mishra(i) and Deepti Singh}

Correction to: Nature Climate Change https://doi.org/10.1038/s41558-021-01276-3, published online 3 February 2022.

In the version of this article initially published, there were typographical errors in the main text. In the third sentence of the "Increasing exposure to compound droughts" section, the text now reading, in part, "droughts during 2071-2100 and 2031-2060, respectively," replaces "droughts during 2031-2060 and 2071-2100, respectively." In the Methods "Compound drought characteristics" section, sixth sentence, now reading in part "(less than around -1.65 in CESM and -1.66 in CanESM2)," the minus sign before 1.66 replaces an approximately symbol in the original.

The changes have been made to the HTML and PDF versions of the article.

Published online: 14 March 2022

https://doi.org/10.1038/s41558-022-01340-6

(C) The Author(s), under exclusive licence to Springer Nature Limited 2022 